\title{
AN ITERATIVE SCHEME FOR A SYSTEM OF QUASI VARIATIONAL INEQUALITIES
}

\author{
MuHAmmad Aslam NoOR ${ }^{1}$ AND ZHenYu HuANG ${ }^{2}$
}

\begin{abstract}
In this paper, we consider a new system of quasi variational inequalities involving two different operators. Using the projection technique, we suggest and analyze a new iterative method for solving this system of quasi variational inequalities. We also prove the convergence of this iterative method under some mild conditions. As a special case, our results include the results of Huang and Noor [6] for solving system of variational inequalities.
\end{abstract}

Mathematics subject classification (2000): 49J40, 65B05, 47H17.

Key words and phrases: quasi variational inequalities, a system of quasi variational inequalities involving two different operators, relaxed $(\gamma, r)$-cocoercive mappings.

\section{REFERENCES}

[1] C. BAIOCCHI, A. CAPELO, Variational and Quasi Variational Inequalities, Wiley, New York, 1984.

[2] P. Daniele, F. GianNessi, AND A. MAUgeri, Equilibrium problems and variational models, Kluwer Academic Publishers, United Kingdom, 2003.

[3] F. Giannessi AND A. MAUGERI, Variational inequalities and network equilibrium problems, Plenum Press, New York, 1995.

[4] F. GianNessi, A. MAUgeri AND P. M. PARdalos, Equilibrium problems, nonsmooth optimization and variational inequalities problems, Kluwer Academic Publishers, Dordrecht Holland, 2001.

[5] R. Glowinski, J. L. Lions and R. TREMOLIERES, Numerical analysis of variational inequalities, North-Holland, Amsterdam, Holland, 1981.

[6] ZHENYU HUANG AND M. ASLAM NOOR, An explicit projection method for a system of nonlinear variational inequalities with different $(\gamma, r)$-cocoercive mappings, Applied Mathematics and Computation (2007) (in press)

[7] M. Mosco, Implicit variational problems and quasi-variational inequlities, Nonlinear Operators and the Calculus of Variations, Lecture Notes in Mathematics, Springer Verlag, New York, New York, 543, pp. 83-126, 1976.

[8] A. NAgURNEY, D. Zhang, Projected Dynamical Systems and Variational Inequalities with Applications, Kluwer Academic Publishers, Dordrecht, 1996.

[9] M. ASLAM NOOR, Sensitivity analysis for quasi-variational inequalities, Journal of Optimization Theory and Applications 95(2) (1997), 399-407.

[10] M. ASLAm NoOR, Generalized quasi variational inequalities and implicit Wiener-Hopf equations, Optimization 45 (1999), 197-222.

[11] M. ASLAm NOOR, Extragradient method for pseudomonotone variational inequalities, Journal of Optimization Theory and Applications 117 (2003) 475-488.

[12] M. Aslam NoOR, Some developments in general variational inequalities, Applied Mathematics and Computation 152 (2004), 199-277.

[13] M. PATRIKSSON, Nonlinear Programming and Variational Inequalities: A Unified Approach, Kluwer Academic Publishers, Dordrecht, 1998.

[14] R. U. VERMA, Generalized system for relaxed cocoercive variational inequalities and projection methods, Journal of Optimization Theory and Applications 121(1) (2004), 203-210. 
[15] X. L. WenG, Fixed point iteration for local strictly pseudocontractive mappings, Proceedings of the American Mathematical Society 113 (1991), 727-731.

[16] D. L. ZHU AND P. MARCOTTE, Cocoercivity and its role in the convergence of iterative schemes for solving variational inequalities, SIAM J. Optimization 6(1996), 714-726. 